\title{
CHEMICAL DETECTION OF SEX AND CONDITION IN THE CRAYFISH Orconectes virilis
}

\author{
BRIAN A. HAZLETT \\ Division of Biological Sciences, University of Michigan \\ Ann Arbor, Maine 48109-1048
}

(Received March 24, 1984; accepted June 4, 1984)

\begin{abstract}
Individual crayfish (Orconectes virilis) were tested for responses to water containing conspecific individuals of several sex-status categories. Isolated males did not react to "self" water but did show aggressive postures while isolated, nonself male water was introduced. Males' responses to female water was different from responses to male water. Water from aggressing males elicited fewer agonistic postures and more "neutral" postures. Females showed little difference in response to waters from different categories of conspecifics.
\end{abstract}

Key Words-Chemical detection, Orconectes virilis, crayfish, sex recognition, stress.

\section{INTRODUCTION}

The utilization of chemical information by animals is widespread in all environments, and freshwater systems are no exception. Changes in behavior following detection of waterborne chemicals produced by conspecifics have been documented for a variety of species and behavioral situations. The responses of crayfish (Family Cambaridae) to waterborne substances illustrate well the ways in which chemicals can influence behavior.

Recognition of maternal condition by young crayfish was demonstrated by Little (1975, 1976) for Orconectes sanborni and Procambarus clarkii. Tierney and Dunham's (1982) study of Orconectes virilis and $O$. propinquus illustrates species recognition by chemical means, while Thorp and Ammerman (1978) provided evidence for the detection of a stress-induced chemical by conspecific individuals of Procambarus acutus. Recognition of sex by chemical means was reported for male Procambarus clarkii (Ameyaw-Akumfi and Hazlett, 1975), but Itagaki and Thorp (1981) concluded that such a capability by $P$. clarkii was not demonstrable by their own experiments. 
The following experiments were designed to examine a number of questions concerning responses to waterborne chemicals in the crayfish Orconectes virilis. Specifically, the responses of isolated males and females to water containing a member of either the same or opposite sex was examined as were possible changes in such responses after pair bonds were formed. In addition, the responses of males to "self" water and water in which agonistically interacting conspecific males were housed were recorded.

\section{METHODS AND MATERIALS}

The experiments were carried out between October and mid-November, 1983, with specimens of Orconectes virilis which had been collected from a stream in Pinckney, Michigan (see Hazlett, et al, 1974, for some ecological details on this population). Specimens were held in unisexual communal aquaria prior to use and were tested within three weeks of collection. Pair bonds are normally formed at this time of year by these crayfish (Ameyaw-Akumfi, 1976; Hazlett, 1983). All individuals were sexually mature (45-60 mm cephalothorax length), and all males were form I.

Animals to be tested were placed in visually isolated $50 \times 25-\mathrm{cm}$ aquaria with $10 \mathrm{~cm}$ of well water. "Source" animals were placed in $18 \times 26-\mathrm{cm}$ aquaria with $15 \mathrm{~cm}$ of well water and a clay pot for shelter. Both test and source aquaria were continually aerated. Both test and source animals were allowed to settle in their aquaria for $24 \mathrm{hr}$ prior to testing to avoid any stress associated with transfer. Tests were run between 1300 and $1700 \mathrm{hr}$, and the crayfish were fed daily after testing.

For each test, 5-mm-diameter tubing was arranged from a source aquarium to the test aquarium emptying in the corner opposite the test crayfish's initial position. The observer positioned himself about $1 \frac{1}{2} \mathrm{~m}$ from the test tank. After a 10-minute period, a peristaltic pump (Masterflex Speed Controller) was activated which delivered water from the source to test aquarium at the rate of 250 $\mathrm{ml} / 10 \mathrm{~min}$. For the next $10 \mathrm{~min}$, the posture of the test crayfish was recorded. The tubing was rinsed with well water between tests.

The postures were categorized into three levels for each of three parts of the crayfish. The chelipeds were either lowered (long axis of mani between parallel to substrate and a $20^{\circ}$ angle with substrate, tips of dactyls in contact with substrate), neutral (long axis of mani at $25-40^{\circ}$ angle to the substrate, tips within a few millimeter of substrate), or raised (long axis of mani parallel to substrate or higher with tips at least $10 \mathrm{~mm}$ from substrate). The chephalothorax was categorized as either lowered (coxae of walking legs in contact with substrate), neutral (normal walking position, coxae of walking legs less than $10 \mathrm{~mm}$ above substrate) or raised (body elevated, coxae of walking legs $10 \mathrm{~mm}$ or more 
Table 1. Condition of Observed Crayfish and Source Water Aquarium for Different Test Situations

\begin{tabular}{ll}
\hline Observed Crayfish & Source water condition \\
\hline 1. Isolated male & isolated male \\
2. Isolated female & isolated male \\
3. Isolated male & isolated female \\
4. Isolated female & isolated female \\
5. Isolated male & same male (self) \\
6. Isolated male & two aggressing males \\
7. Paired male & isolated male \\
8. Paired female & isolated male \\
9. Paired male & isolated female \\
10. Paired female & isolated female \\
\hline
\end{tabular}

above substrate). The abdomen was categorized as curled (telson under anterior segments of abdomen), neutral (abdomen almost straight but telson perpendicular to substrate), or extended (abdomen straight with telson parallel to substrate, uropods spread). The data for each test were the number of seconds, during the 10-min observation period, with the parts in each of the described positions. The results were analyzed by ANOVAs with pairwise comparisons. During the pretrial period, crayfish were usually in a lowered, chelae-down position in a corner of the aquarium.

Each test crayfish was observed under two to four test conditions but was used in any one type of test only once. The sequence of test conditions of isolated test animals was randomized, although the paired test conditions were run later for the most part to allow testing of individuals before and after pairing.

The status and conditions of test and source animals are listed in Table 1. There were 11 replicates for each of the 10 types of tests. For the "self" tests with male $O$. virilis, water from the test animal's aquarium was circulated by the peristaltic pump back to the same aquarium. For the "agonistic stress" source condition, a second male $O$. virilis was placed in the source aquarium with a previously isolated male just ten minutes before the start of observations; in all cases the animals in the source aquarium actively engaged in agonistic interactions (Rubenstein and Hazlett, 1975) for the duration of the observations. For the "paired" test animals, a male and female were placed together with a large clay pot for a shelter. They were allowed to interact for at least two days and were judged to be paired if they cohabited the pot with no aggressive displays exchanged for two days or if they were observed in copulation. The pair was observed together (in the same aquarium) during a test and postures recorded for both when water from a source aquarium was introduced. 
The means of the number of seconds spent in the various postures during the observation periods are shown in Table 2 . The intermediate abdomen posture was observed so infrequently that it is not included in the table. The "neutral" postures of the chelipeds and body were also infrequent overall. Thus the crayfishes' parts were primarily raised or lowered. This means the two measures (time spent raised, time spent lowered) are not independent (Cane, 1963) since the value of one sets the value of the other in most situations. For this reason, only one set of variables can be examined and the raised/extended variables were analyzed by ANOVA (Table 3), since those postures were the most different from the resting postures observed during the pretrial periods. Only those comparisons which could answer a biologically interesting or meaningful question were examined (i.e., a number of comparisons which made no sense are not included in Table 3).

As shown in Table 3, there were a number of significant differences among the treatment groups in the times spent with the chelipeds raised (overall $F$ statistic $=3.13, P=0.0023$ ) and body raised (overall $F=3.07, P=0.0027$ ). The pattern of differences was very similar for these two postures. The times spent with the abdomen extended did not vary among the treatment groups (overall $F=1.63, P=0.1150$ ).

The responses of female $O$. virilis showed very few differences among treatments. Females showed no differences in responses to male and female water ( 2 vs. 4). Paired females did not differ from isolated females in their responses to female water (4 vs. 10). Paired females had the abdomen extended less than isolated females when male water was introduced $(P=0.03)$ but otherwise there were no differences.

Male $O$. virilis responded differently, although marginally, to male and female water in the time spent with the chelipeds raised and body raised ( 1 vs. 3). Males' responses to isolated males was different from that of females' (1 vs. 2) but there was no difference for isolated males and females in the responses to female water (3 vs. 4 ).

Males clearly distinguished between water inhabited by another male $O$. virilis and water inhabited by that same individual male ( 1 vs. 5). "Self" water introduction elicited no visible responses from test males whereas water from similar-but-nonself male $O$. Virilis frequently elicited raised chelipeds and cephalothorax.

Males also behaved very differently when water from aggressing males was introduced as compared to water from an isolated male ( 1 vs. 6). Raised chelipeds and body postures were less frequent and neutral postures more common.

Males which were paired with a female behaved very differently towards male water when compared to the behavior shown by isolated males to male water ( 1 vs. 7). The responses to female water by paired and isolated males was 


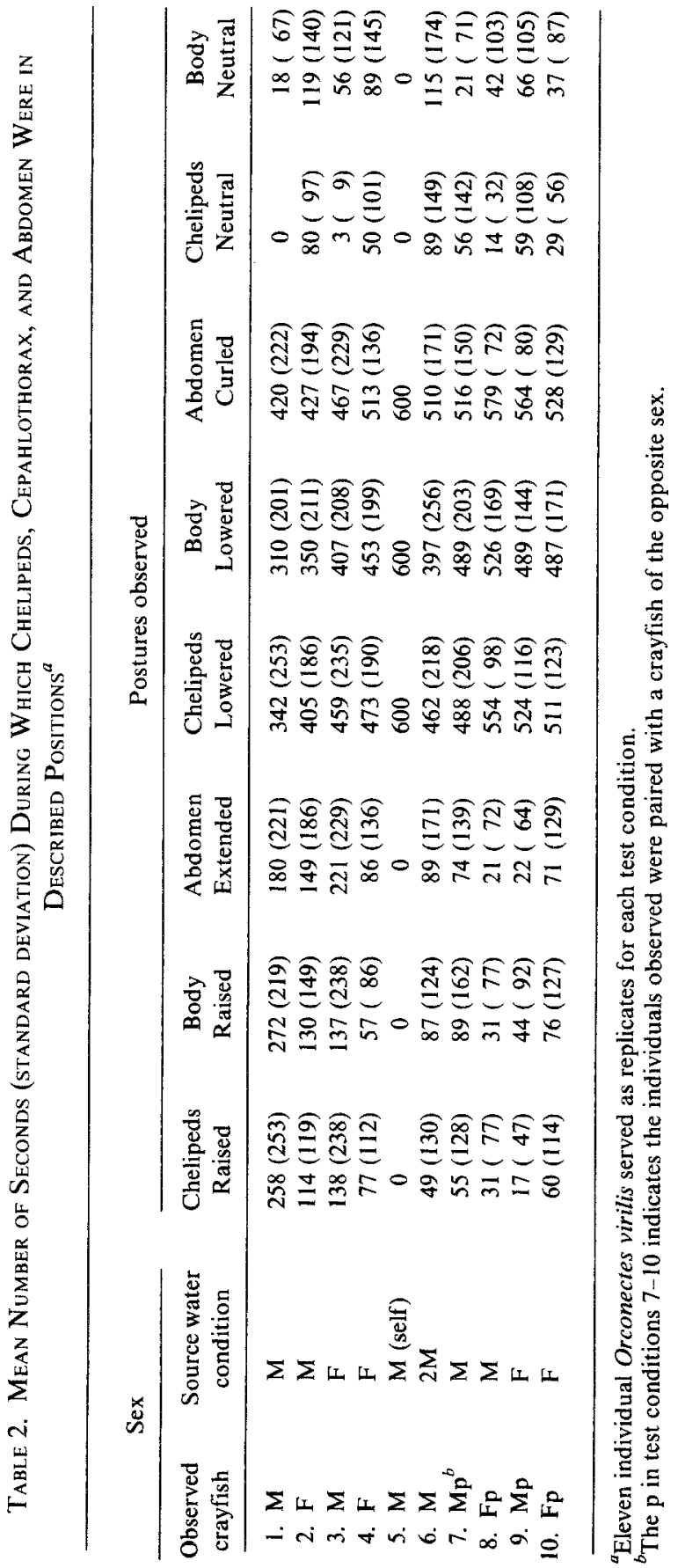


Table 3. Probability Values Associated with $F$ Values from Pairwise Comparisons in ANOVA

\begin{tabular}{llll}
\hline & $\begin{array}{c}\text { Chelipeds } \\
\text { raised }\end{array}$ & $\begin{array}{c}\text { Body } \\
\text { raised }\end{array}$ & $\begin{array}{c}\text { Abdomen } \\
\text { extended }\end{array}$ \\
\hline $\begin{array}{l}\text { Male responses } \\
\text { 1 vs. } 2\end{array}$ & 0.012 & 0.016 & 0.622 \\
1 vs. 3 & 0.052 & 0.032 & 0.469 \\
1 vs. 5 & 0.000 & 0.000 & 0.011 \\
1 vs. 6 & 0.001 & 0.004 & 0.186 \\
1 vs. 7 & 0.001 & 0.003 & 0.103 \\
3 vs. 4 & 0.290 & 0.178 & 0.469 \\
3 vs. 9 & 0.043 & 0.125 & 0.090 \\
Female responses & & & \\
2 vs. 4 & 0.499 & 0.190 & 0.287 \\
2 vs. 8 & 0.142 & 0.084 & 0.035 \\
4 vs. 10 & 0.767 & 0.738 & 0.805 \\
\hline
\end{tabular}

different only in the frequency of raised chelipeds, paired males being less likely to show that posture ( 3 vs. 9 ).

\section{DISCUSSION}

The results of these experiments indicate that male Orconectes virilis react differently to water in which conspecifics of several categories of sex and status were held. The lack of differential responses to male and female water by female $O$. virilis may well represent an inability to detect any possible differences in chemicals by females. However, the possibility that both visual and chemical stimuli must be detected at the same time, as in the blue crab Callinectes sapidus (Teytaud, 1971), cannot be ruled out. Alternatively, the measures taken may not have been appropriate to detect any differences in behavioral responses. In paired interactions, females tend to be somewhat aggressive towards both males and females (until pair bonds are formed with a male and then aggression, at least towards that male, decreases). In these tests, the postures associated with the agonistic behavior were just as frequently shown by females when male or female water was introduced. Response of females to "self" and stressed conspecifics will be measured in future tests.

As reported earlier for Procambarus clarkii (Ameyaw-Akumfi and Hazlett, 1975), males of $O$. virilis exposed to water in which a male conspecific was held maintained postures associated with aggression while introduction of female water was associated with lowered postures. It is interesting to note that males often maintained raised chelipeds and cephalothorax for 10-15 min after the introduction of male water had stopped, indicating either a persistence of a 
behavioral tendency induced in the male or persistence of a chemical for some minutes (or both). Interestingly, in both the present study of $O$. virilis and Itagaki and Thorp's (1981) study of $P$. clarkii, the cheliped raised posture (the only one in common for the two studies) was (1) significantly different among all treatments (overall $F$ value significant) and (2) often different for males and females exposed to the same treatment. The differences in conclusions of the two studies concern the responses of males to male and female water; in their comparison of male cheliped-raised duration, Itagaki and Thorp (1981, Table 2) state that the $P$ value for that comparison was " $>0.05$ " - which is also true in the present study where $P=0.052$, i.e., greater than 0.05 . Given that it was one of just three parameters tested in this study, it seems reasonable to suggest that the present results show a differential in cheliped-raised duration as well as in bodyraised duration.

When males were paired, they did not respond with raised postures to male water. This difference in behavior must be interpreted with caution since there was a shelter in the test animals' aquarium and, in addition, the two animals in the observation aquarium presumably affected each other's behavior in a complex manner during the test period. Responses of one member of a pair following removal of the other member would be difficult to interpret, and those tests were not attempted.

The lack of any response to "self" water was very marked. This differential in time of postures maintained was clear and serves as an interesting control for the testing procedure. Discrimination of self as compared to others of the same species and sex is not surprising and has been reported for other crustaceans (Caldwell, 1979, 1984). The differences in behavior of male $O$. virilis exposed to self water and male $P$. clarkii exposed to water with no crayfish in the container (condition C of Itagaki and Thorp, 1981) is striking, even though the test conditions are similar in many ways. All male $O$. virilis spent the entire observation period in a lowered position, not moving. The male $P$. clarkii (Itagaki and Thorp, 1981, Figure 1) spent a considerable portion of the observation period "climbing" and showing "gross body movement" and executed more "chelae waving" than under any other condition. The control level behaviors of the crayfish appear to have been very different in the two studies.

This apparent difference in behaviors shown under control conditions in the two studies could be a function of the species of crayfish studied. Alternatively, the primarily lentic $P$. clarkii may not have adapted well to the flow-through system utilized by Itagki and Thorp (1981). In the present study and previous work (Ameyaw-Akumfi and Hazlett, 1975), a nonflowing system was chosen since it more closely resembles conditions in the natural environment. In the Pinckney populations of Orconectes virilis, adult males and females form pair bonds in the fall (Ameyaw-Akumfi, 1976) and the pair (plus occasional additional females) are partially sealed off in special burrows (Hazlett, 1983). At the time of year when the experiments were done, adult $O$. virilis live in an almost static 
system. If chemical communication occurs at that time, it would have to operate in a nonflowing environment. See Hazlett (1984) and Thorp (1984) for additional discussion of this point.

The difference in responses of male $O$. virilis to water containing one, apparently undisturbed male conspecific and two, aggressing conspecifics is striking. Rather than showing raised postures, the response shown by crayfish exposed to an identifiable source of potential danger, the test individuals spent more time in the other positions. With due caution concerning an excess of statistical tests, the times spent in the neutral postures by test males were greater when the source water contained aggressively interacting crayfish $(P=0.046$ for cheliped neutral, $P=0.037$ for cephalothorax neutral comparing test conditions 1 and 6 by ANOVA). The crayfish behaved as if they detected a low level of disturbance of an unspecified nature, rather than responding to a known source of distrubance (by raising the chelipeds). Clearly there is an important design flaw in these comparisons since both the number (one vs. two) of crayfish and the conditions (undisturbed vs. aggressing) vary. Therefore the reason for differences in responses is somewhat open to interpretation. Since two males in an aquarium frequently aggress, a more complicated delivery of source water will be necessary to compare water containing one and two undisturbed male conspecifics. Unlike the responses to isolated males, the responses to stressed males appeared to cease within a minute after the introduction of water was stopped, possibly indicating shorter persistence of the chemical(s).

In some pilot tests, before the peristaltic pump was utilized for water delivery, rapid changes in test animal behavior toward isolated male water was noticed when the source male was disturbed by experimenter manipulation of the tubing to the source aquarium. The raised postures which had been shown towards undisturbed male water ceased within seconds following disturbance of the source male. Tests to determine if other means of source animal disturbance result in a detection of chemicals by conspecific individuals are planned.

The responses of crayfish to water containing disturbed conspecifics is quite distinct from the classic Schreckstoff situation (von Frisch, 1938), where animals respond to physically damaged conspecifics (Atema and Stenzler, 1977; Landauer and Chapnick, 1981; Stenzler and Atema, 1977). Responses to undamaged but disturbed conspecifics have been reported for other crustaceans. Thorp and Ammerman, (1978) reported responses to stress pheromones in the crayfish Procambarus acutus. Hazlett (1966) demonstrated avoidance by the hermit crab Clibanarius tricolor of water from an aquarium containing stressed individuals of a fiddler crab (Uca rapax) or aggressing individuals of a spider crab (Mithrax verrucosus). Clearly, additional tests on crustaceans, including Orconectes virilis and other crayfish, are needed to differentiate between responses to generalized stress-related chemicals and alarm pheromones.

Acknowledgments - Thanks are given to Karsten Hazlett for aid in field collections and to Dan Rittschof and Catherine Bach for their comments on the manuscript. 


\section{REFERENCES}

ATEMA, J., and STENZLER, D. 1977. Alarm substance of the marine mud snail, Nassarius obsoletus: Biological characterization and possible evolution. J. Chem. Ecol. 3:173-187.

AMEYAW-AKUMFI, C.E. 1976. Some aspects of breeding biology of crayfish. PhD dissertation. University of Michigan, Ann Arbor, $252 \mathrm{pp}$.

AmEYAW-AKumFI, C. 1979. Appeasement displays in cambarid crayfish (Decapoda, Astacoidea). Crustaceana, Suppl. 5:135-141.

AmeYaw-Akumfi, C., and HAZlett, B.A. 1975. Sex recognition in the crayfish Procambarus clarkit. Science 190:1225-1226.

CALDWELL, R.L. 1979. Cavity occupation and defensive behaviour in the stomatopod Gonodactylus festae: Evidence for chemically mediated individual recognition. Anim. Behav. 27:194-201.

Caldwell, R.L. 1984. A test of individual recognition in the stomatopod Gonodactylus festae. Anim. Behav. In press.

CANE, V. 1963. Some ways of describing behaviour, pp. 361-388, in W.H. Thorpe and O.L. Zangwill (eds.). Current Problems in Animal Behaviour. Cambridge University Press, London.

Hazlett, B.A. 1966. Social behavior of the Paguridae and Diogenidae of Curacao. Stud. Fauna Curacao 23:1-143.

Hazlett, B.A. 1983. Parental behavior in decapod Crustacea, pp. 171-193, in Studies in Adaptations, The Behavior of Higher Crustacea. S. Rebach and D. Dunhams (eds.). Wiley \& Sons, New York.

HAzLETT, B.A. 1984. Experimental design and ecological realism. J. Chem. Ecol. 10:1281-1282.

HAZLETT, B.A., RitTSCHOF, D., and RUBENSTEIN, D. 1974. Behavioral biology of the crayfish Orconectes virilis I. Home range. Am. Midl. Nat. 92:301-319.

ITAGAKI, H., and I THORP, J.H. 1981. Laboratory experiments to determine if crayfish can communicate chemically in a flow-through system. J. Chem. Ecol. 7:115-126.

LANDAUER, M.R., and CHAPNICK, S.D. 1981. Responses of terrestrial slugs to secretions of stressed conspecifics. Psychol. Rep. 49:617-618.

LITTLE, E.E. 1975. Chemical communication in maternal behavior of crayfish.Nature 255:400-401.

LiTTLE, E.E. 1976. Ontogeny of maternal behavior and brood pheromone in crayfish. J. Comp. Physiol. 112:133-142.

ROSE, R.D. 1982. On the nature of chemical communication by crayfish in a laboratory controlled flow-through system. J. Chem. Ecol. 8:1065-1071.

RUBENSTEIN, D.I., and HAZLETT, B.A. 1974. Examination of the agonistic behavior of the crayfish Orconectes virilis by character analysis. Behaviour 50:193-216.

STENZLER, D., and ATEMA, J. 1977. Alarm response of the marine mud snail, Nassarius obsoletus: Specificity and behavioral priority. J. Chem. Ecol. 3:159-171.

TEYTAUD, A.R. 1971. The laboratory study of sex recognition in the blue crab Callinectes sapidus Rathbun. Sea Grant Tech. Bull. 15:1-63.

TIERNEY, A.J., and DunhaM, D.W. 1982. Chemical communication in the reproductive isolation of the crayfishes Orconectes propinquus and Orconectes virilis (Decapoda, Cambaridae). J. Crust. Biol. 2:544-548.

THORP, J.H. 1984. Theory and practice in crayfish communication studies. J. Chem. Ecol. 10:12831287.

THORP, J.H., and AMMERMAN, K.S. 1978. Chemical communication and agonism in the crayfish Procambarus acutus acutus. Am. Midl. Nat. 100:471-474.

THORP, J.H., and ITAGAKI, H. 1982. Verification versus falsification of existing theory: Analysis of possible chemical communication in crayfish. J. Chem. Ecol. 8:1073-1077.

VONFrISCH, K. 1938. Zur psychologie des Fisch-Schwarmes. Naturwissenschaften 26:601-606. 